\title{
Body Composition in Crohn's Disease and Ulcerative Colitis: Correlation with Disease Severity and Duration
}

\author{
Dawesh P. Yadav, ${ }^{1}$ Saurabh Kedia, ${ }^{1}$ Kumble Seetharama Madhusudhan, ${ }^{2}$ \\ Sawan Bopanna, ${ }_{1}$ Sandeep Goyal, ${ }^{1}$ Saransh Jain, ${ }^{1}$ Naval K. Vikram, ${ }^{3}$ Raju Sharma, \\ Govind K. Makharia, ${ }^{1}$ and Vineet Ahuja ${ }^{1}$ \\ ${ }^{1}$ Department of Gastroenterology and Human Nutrition, All India Institute of Medical Sciences, New Delhi 110029, India \\ ${ }^{2}$ Department of Radiodiagnosis, All India Institute of Medical Sciences, New Delhi 110029, India \\ ${ }^{3}$ Department of Medicine, All India Institute of Medical Sciences, New Delhi 110029, India
}

Correspondence should be addressed to Vineet Ahuja; vineet.aiims@gmail.com

Received 13 June 2017; Revised 5 August 2017; Accepted 20 August 2017; Published 31 October 2017

Academic Editor: Maikel P. Peppelenbosch

Copyright (C) 2017 Dawesh P. Yadav et al. This is an open access article distributed under the Creative Commons Attribution License, which permits unrestricted use, distribution, and reproduction in any medium, provided the original work is properly cited.

\begin{abstract}
Background. Results on body composition in Crohn's disease (CD) and ulcerative colitis (UC) have been heterogeneous and are lacking from Asia. Present study assessed body composition in CD/UC and correlated it with disease severity/duration. Methods. Patients of CD/UC following between Dec 2014 and Dec 2015 who consented for bioimpedance analysis for body fat measurement were included. Lean mass and fat-free mass index (FFMI) were calculated with standard formulae. Visceral fat area (VFA), subcutaneous fat area (SCA), and visceral to subcutaneous fat ratio (VF/SC) were evaluated in CD patients on abdominal CT. Results. Lean mass in CD ( $n=44$, mean age: $41.2 \pm 15.8$ years, $73 \%$ males) was significantly lower than UC ( $n=53$, mean age: $33.2 \pm 11.2$ years, $68 \%$ males; $44.2 \pm 7.8$ versus $48.3 \pm 8.4 \mathrm{Kg}, p=0.01)$. In both $\mathrm{UC} / \mathrm{CD}$, disease severity was associated with nonsignificant decline in BMI (UC: $22.1 \pm 4.9$ versus $20.2 \pm 3.2$ versus $19.9 \pm 3.2 \mathrm{~kg} / \mathrm{m}^{2}, p=0.23$; CD: $22.1 \pm 4.2$ versus $19.9 \pm 2.3$ versus $19.7 \pm 4.2 \mathrm{~kg} / \mathrm{m}^{2}, p=0.18$ ) and fat mass (UC: $10.9 \pm 8.9$ versus $8.1 \pm 5.9$ versus $5.7 \pm 3.6 \mathrm{~kg}, p=0.14$; CD: $11.2 \pm 7$ versus $7.9 \pm 4.4$ versus $7.2 \pm 5.9 \mathrm{~kg}, p=0.16)$, and disease duration was associated with significant decline in FFMI $(p<0.05)$. In CD, disease severity was associated with nonsignificant decline in SCA and increase in VF/SC. Conclusions. CD patients have lower lean mass than UC. Body fat decreases with increasing disease severity and fat-free mass decreases with increasing disease duration in both UC/CD.
\end{abstract}

\section{Introduction}

There has been a recent rise in the disease burden of inflammatory bowel disease (IBD) in India and other Asian countries and as per a recent report, the overall number of IBD patients in India is second highest in the world after USA [1-3]. This increase will gradually burden the healthcare system and will put increasing pressure on the IBD physician for optimal care of patients. The optimal IBD care dose not only include the control of disease activity with immune based therapies, but also include improvement in quality of life, part of which is compromised by poor nutritional status of the patient which may be caused by low dietary intake, changes in metabolism, increased intestinal protein loss, and nutrient malabsorption [4]. The conventional indices for assessment of nutritional status such as body mass index (BMI) have been suboptimal and therefore require better modalities such as fat mass and fat percentage (for assessment of body fat) and fat-free mass index (FFMI) and lean mass (for assessment of fat-free mass) which can be assessed by bioimpedance analysis or DEXA (dual energy X-Rat absorptiometry) $[5,6]$. There are several recent reports which have assessed and compared body composition with these techniques in patients with Ulcerative colitis (UC) as well as Crohn's disease (CD), but the results from these studies have been heterogeneous and inconsistent and very few of these studies are from Asian countries [7-11]. The distribution of body fat is different between Asians and Caucasians and 
therefore the results from West cannot be extrapolated to Asian patients. Abdominal fat (visceral and subcutaneous fat and visceral to subcutaneous fat ratio) has also studied in IBD and studies have inconsistently linked visceral fat to severity of CD and postoperative recurrence of CD [12-15].

This study was therefore planned to compare body composition between patients of UC and CD, correlate body composition with disease severity and duration in both UC and $\mathrm{CD}$ patients, correlate body composition with disease behavior in CD and disease extent in UC, and correlate abdominal fat with disease behavior, severity, and disease duration in CD patients.

\section{Materials and Methods}

2.1. Patient Population. Adult patients with diagnosis of ulcerative colitis and Crohn's disease attending the inflammatory bowel diseases (IBD) clinic at All India Institute of Medical Sciences, New Delhi, India, from Dec 2014 to Dec 2015, were screened for inclusion in the study. Of these, patients who consented for bioimpedance analysis were included in the study. Written informed consent was obtained from all patients included in the study. Institutional ethics committee approved the study.

2.2. Study Design. In this prospective study, patients with UC and CD were subjected to a uniform clinical evaluation including detailed history and examination, laboratory assessment, endoscopy (UGI endoscopy or colonoscopy as appropriate), and mucosal biopsies. Patient data was collected on their demographics, clinical, endoscopic, histologic, and radiologic features and treatment given and its response. All patients underwent body fat measurement with the bioimpedance machine. In addition, visceral fat area, subcutaneous fat area, and visceral to subcutaneous fat ratio (VF/SC) was evaluated in patients with Crohn's disease with the help of abdominal CT.

\subsection{Definitions}

2.3.1. Crohn's Disease. The patients were diagnosed as CD on the basis of the European Crohn's and Colitis Organization (ECCO) guidelines, with a combination of clinical, endoscopic, and histological features [16]. The location and behavior of Crohn's disease were classified as per Montreal classification [17]. Severity of CD was measured by Crohn's disease activity index (CDAI) [18].

2.3.2. Ulcerative Colitis. Diagnosis of ulcerative colitis was made on the basis of European Crohn's and Colitis Organization (ECCO) guidelines with a combination of clinical symptoms like bloody diarrhoea and endoscopic appearance and histological findings compatible with ulcerative colitis [19]. Disease activity in UC was measured by Simple Clinical Colitis Activity Index [20] and endoscopic severity was assessed by Baron's endoscopic score [21].

2.3.3. Technique of Measuring Total Body Fat. Total body fat was measured by leg to leg bioimpedance machine (TANITA body composition analyzer, model TBF-215) in patients of ulcerative colitis and Crohn's disease [22]. Subjects were asked to stand barefoot on the metal sole plates of the machine, and age, gender, and height details were entered manually into the system via a keyboard. Body weight and percentage body fat, estimated using the standard built in prediction equations for adults, were displayed on the machine and printed out.

2.3.4. Technique of Measuring Lean Mass and Fat-Free Mass Index. Lean mass was calculated with the following formula:

Lean mass $=$ Body weight $*(1-($ body fat $\% / 100))$.

Fat-free mass index (FFMI) was calculated with the following formula:

FFMI $=($ Lean mass $/ 2.2) /\left((\text { Height in meters })^{2} \times\right.$ 2.20462).

2.3.5. Technique of Measuring Visceral Fat. Visceral fat (VF) and subcutaneous fat (SC) area were measured at the level of umbilicus (L4 vertebrae level) with the patient in supine position by multislice CT scanner (Siemens, Erlangen, Germany) in all the patients. The technique used for fat tissue measurements on CT has been standardized and validated [23]. The VF area was defined as all the pixels with adipose tissue attenuation coefficients. The tomographic attenuation of adipose tissue was defined to be between -150 and -50 Hounsfield units. The CT measurement was done by a radiologist blinded to the clinical data.

2.4. Statistical Analysis. Qualitative data was expressed as frequency and percentage. Quantitative data was expressed as mean \pm SD if normally distributed and as median (interquartile range) when the data distribution was skewed. BMI, fat percentage, fat mass, lean mass, and FFMI were compared between CD and UC by Student's $t$-test, and comparison between various UC and CD subgroups according to disease extent, location, and behavior; clinical and endoscopic severity; and steroid requirement and disease duration was done by ANNOVA test. $p$ value of $<0.05$ was considered as statistically significant. Data was analyzed by using statistical software SPSS, version 20.

\section{Results}

3.1. Baseline Clinical and Demographic Characteristics. A total of 53 patients with ulcerative colitis and 44 patients with Crohn's disease were enrolled in the study (Table 1). Mean age of the UC and CD patients was $33.2 \pm 11.2$ years and $41.2 \pm 15.8$ years, respectively. About two-thirds of patients were males in both the groups. Median duration of symptoms in UC and CD patients was 24 (IQR, 12-48) and 36 (IQR, 18-105) months, respectively. Among the UC patients, 5.6\% patients had proctitis, $66 \%$ had left sided colitis, and $28.3 \%$ had pancolitis. Among CD patients, disease location was L1 in $47.7 \%$, L2 in $22.7 \%$, L3 in $25 \%$, and L4 in $22.7 \%$ patients; and disease behavior was inflammatory in $45.7 \%$, stricturing 
TABLE 1: Baseline characteristics of patients of ulcerative colitis and Crohn's disease.

\begin{tabular}{|c|c|c|c|}
\hline & $\mathrm{UC}(N=53)$ & $\mathrm{CD}(N=44)$ & $p$ value \\
\hline \multicolumn{4}{|l|}{ Parameters } \\
\hline Age in years, mean \pm SD & $33.2 \pm 11.2$ & $41.2 \pm 15.8$ & 0.01 \\
\hline Sex, male $(n, \%)$ & $36(67.9 \%)$ & $32(72.7 \%)$ & 0.61 \\
\hline Duration of symptoms (months), median & $24(12-48)$ & $36(18-105)$ & 0.15 \\
\hline Haemoglobin, g/dL, mean \pm SD & $11.8 \pm 2.5$ & $10.8 \pm 2.9$ & 0.02 \\
\hline Albumin, g/dL, mean \pm SD & $4.2 \pm 0.5$ & $4.0 \pm 0.8$ & 0.11 \\
\hline Extent/location of disease & $\begin{array}{c}\text { E1: } 3(5.6 \%) \\
\text { E2: } 35(66 \%) \\
\text { E3: } 15(28.3 \%)\end{array}$ & $\begin{array}{c}\text { L1: } 21(47.7 \%) \\
\text { L2: } 10(22.7 \%) \\
\text { L3: } 11(25 \%) \\
\text { L4: } 10(22.7 \%)\end{array}$ & \\
\hline Disease behavior & & $\begin{array}{l}\text { B1: } 21(45.7 \%) \\
\text { B2: } 23(50 \%) \\
\text { B3: } 2(4.3 \%)\end{array}$ & \\
\hline \multicolumn{4}{|l|}{ Treatment received } \\
\hline 5-ASA & $53(100)$ & $10(22.7)$ & \\
\hline Steroids & $16(30.2)$ & $29(65.9)$ & \\
\hline Immunomodulators & $17(32.1)$ & $26(40.9)$ & \\
\hline Biologics & $0(0)$ & $0(0)$ & \\
\hline
\end{tabular}

E1: proctitis; E2: left sided colitis; E3: pancolitis; L1: terminal ileum \pm caecum; L2: colonic; L3: ileocolonic; L4: proximal small intestine; B1: inflammatory; B2: stricturing; B3: penetrating; p: perianal; ASA: aminosalicylic acid.

in $50 \%$ and fistulizing in $4.3 \%$ patients. There was significant correlation between subcutaneous fat and fat mass $(r=0.9$, $p<0.001)$. The treatment details of these patients have been mentioned in Table 1.

3.2. Comparison of Body Composition between CD and UC Patients. There was no significant difference in the mean $\mathrm{BMI}$, fat percentage, and fat mass between $\mathrm{CD}$ and $\mathrm{UC}$ patients (Table 2). The lean mass in CD patients was significantly lower as compared to UC patients $(44.2 \pm 7.8 \mathrm{~kg}$ versus $48.3 \pm 8.4 \mathrm{~kg}, p=0.01$ ) and though not statistically significant, FFMI was also lower in CD as compared to UC patients $(17.2 \pm 1.8$ versus $17.7 \pm 1.9, p=0.09)$.

\subsection{Effect of Disease Extent, Clinical Disease Severity, \\ Endoscopic Severity, Steroid Requirement, and Disease \\ Duration on Body Composition in Patients of Ulcerative Colitis}

3.3.1. Effect of Disease Extent. There was no effect of disease extent on any of the parameters (BMI, fat percentage, fat mass, lean mass, FFMI) (Table 3).

3.3.2. Effect of Clinical Disease Severity. Of 53 patients, 26 were in clinical remission, 17 had mild disease activity, and 10 had moderate to severe disease activity. There was progressive, though not statistically significant, decline in BMI $\left(22.1 \pm 4.9 \mathrm{~kg} / \mathrm{m}^{2}\right.$ versus $20.2 \pm 3.2 \mathrm{~kg} / \mathrm{m}^{2}$ versus $19.9 \pm$ $\left.3.2 \mathrm{~kg} / \mathrm{m}^{2}, p=0.23\right)$, fat percentage $(16.5 \pm 10.2 \%$ versus $13.9 \pm 8.6 \%$ versus $9.7 \pm 4.9 \%, p=0.13)$, and fat mass
TABLE 2: Comparison of body composition between patients of Crohn's disease and ulcerative colitis.

\begin{tabular}{lccc}
\hline Parameters & $\mathrm{UC}(N=53)$ & $\mathrm{CD}(N=44)$ & $p$ value \\
\hline $\begin{array}{l}\text { Body mass index } \\
\left(\mathrm{kg} / \mathrm{m}^{2}\right), \text { mean } \pm \mathrm{SD}\end{array}$ & $21.1 \pm 4.2$ & $20.5 \pm 3.7$ & 0.51 \\
$\begin{array}{l}\text { Fat percentage, mean } \\
\pm \mathrm{SD}\end{array}$ & $14.4 \pm 9.1$ & $15.6 \pm 9.3$ & 0.52 \\
$\begin{array}{l}\text { Fat mass in kg, mean } \\
\pm \mathrm{SD}\end{array}$ & $9.04 \pm 7.5$ & $8.7 \pm 5.9$ & 0.81 \\
$\begin{array}{l}\text { Lean mass in kg, } \\
\text { mean } \pm \mathrm{SD}\end{array}$ & $48.3 \pm 8.4$ & $44.2 \pm 7.8$ & 0.01 \\
$\begin{array}{l}\text { Fat-free mass index } \\
(\text { FFMI }), \text { mean } \pm \mathrm{SD}\end{array}$ & $17.7 \pm 1.9$ & $17.2 \pm 1.8$ & 0.09 \\
\hline
\end{tabular}

$(10.9 \pm 8.9 \mathrm{~kg}$ versus $8.1 \pm 5.9 \mathrm{~kg}$ versus $5.7 \pm 3.6 \mathrm{~kg}, p=0.14)$ with increase in disease severity. However, there was no effect of disease severity on lean mass and FFMI (Table 3).

3.3.3. Effect of Endoscopic Severity. Of 53 patients, 7 patients had grade I, 37 had grade II, and 7 patients had grade III disease as per Baron's endoscopic severity. Patients having grade II and III disease had significantly lower BMI $(20.3 \pm$ $3.8 \mathrm{~kg} / \mathrm{m}^{2}$ versus $20.8 \pm 3 \mathrm{~kg} / \mathrm{m}^{2}$ versus $24.2 \pm 5.3 \mathrm{~kg} / \mathrm{m}^{2}$, $p=0.04)$ and lesser body fat percentage $(12.3 \pm 7.9 \%$ versus $14.7 \pm 5.8 \%$ versus $22.6 \pm 11.4 \%, p=0.01)$ and fat mass (7.4 $\pm 5.9 \mathrm{~kg}$ versus $8.3 \pm 3.7 \mathrm{~kg}$ versus $16.3 \pm 10.8 \mathrm{~kg}, p=0.004)$ as compared to patients having grade I score. However, again there was no effect of endoscopic severity on lean mass and FFMI (Table 3). 
TABLE 3: Effect of disease extent, clinical and endoscopic severity, steroid requirement, and disease duration on body fat and lean mass in patients with ulcerative colitis.

\begin{tabular}{|c|c|c|c|c|c|}
\hline & BMI & Fat percentage & Fat mass in $\mathrm{kg}$ & Lean mass in $\mathrm{kg}$ & FFMI \\
\hline \multicolumn{6}{|l|}{ Disease extent } \\
\hline $\mathrm{E} 1(n=3)$ & $21.9 \pm 4.5$ & $14.6 \pm 9.5$ & $9.4 \pm 6.9$ & $48.6 \pm 8.4$ & $18.5 \pm 2.1$ \\
\hline $\mathrm{E} 2(n=35)$ & $21.3 \pm 4.5$ & $15.1 \pm 10.1$ & $9.6 \pm 8.3$ & $47.3 \pm 8.3$ & $17.8 \pm 2.1$ \\
\hline $\mathrm{E} 3(n=15)$ & $20.2 \pm 3.3$ & $12.8 \pm 6.4$ & $7.4 \pm 5.1$ & $48.3 \pm 8.4$ & $17.5 \pm 1.7$ \\
\hline$p$ value & 0.64 & 0.73 & 0.44 & 0.77 & 0.72 \\
\hline \multicolumn{6}{|l|}{ Disease severity } \\
\hline Remission $(n=26)$ & $22.1 \pm 4.9$ & $16.5 \pm 10.2$ & $10.9 \pm 8.9$ & $49.4 \pm 9.3$ & $18.1 \pm 2.2$ \\
\hline Mild $(n=17)$ & $20.2 \pm 3.2$ & $13.9 \pm 8.6$ & $8.1 \pm 5.9$ & $46.5 \pm 7.3$ & $17.2 \pm 1.9$ \\
\hline Moderate to severe $(n=10)$ & $19.9 \pm 3.2$ & $9.7 \pm 4.9$ & $5.7 \pm 3.6$ & $48.6 \pm 7.8$ & $17.9 \pm 1.9$ \\
\hline$p$ value & 0.23 & 0.13 & 0.14 & 0.54 & 0.36 \\
\hline \multicolumn{6}{|l|}{ Endoscopic severity ${ }^{*}$} \\
\hline Grade I $(n=7)$ & $24.2 \pm 5.3$ & $22.6 \pm 11.4$ & $16.3 \pm 10.8$ & $51.9 \pm 8.2$ & $18.3 \pm 1.6$ \\
\hline Grade II $(n=37)$ & $20.3 \pm 3.8$ & $12.3 \pm 7.9$ & $7.4 \pm 5.9$ & $47.6 \pm 8.5$ & $17.6 \pm 2.1$ \\
\hline Grade III $(n=9)$ & $20.8 \pm 3$ & $14.7 \pm 5.8$ & $8.3 \pm 3.7$ & $47.7 \pm 7.9$ & $17.7 \pm 1.9$ \\
\hline$p$ value & 0.04 & 0.01 & 0.004 & 0.37 & 0.62 \\
\hline \multicolumn{6}{|l|}{ Steroid requirement } \\
\hline None $(n=14)$ & $22.1 \pm 5.3$ & $16.7 \pm 10.9$ & $11.1 \pm 10.1$ & $48.1 \pm 9.4$ & $17.9 \pm 2.0$ \\
\hline $1 /$ year $(n=15)$ & $20.8 \pm 3.6$ & $12.8 \pm 7.1$ & $7.5 \pm 4.6$ & $48.9 \pm 8.1$ & $18.0 \pm 1.9$ \\
\hline \multirow[t]{2}{*}{$>1 /$ year $(n=24)$} & $20.6 \pm 3.9$ & $14.1 \pm 9.2$ & $8.8 \pm 7.1$ & $48.1 \pm 8.2$ & $17.5 \pm 1.9$ \\
\hline & 0.59 & 0.50 & 0.41 & 0.95 & 0.62 \\
\hline \multicolumn{6}{|l|}{ Disease duration (years) } \\
\hline$<1$ year $(n=9)$ & $21.4 \pm 2.9$ & $14.5 \pm 6.1$ & $8.5 \pm 4.5$ & $47.6 \pm 9.3$ & $18.1 \pm 1.7$ \\
\hline $1-5$ years $(n=20)$ & $21.9 \pm 4.8$ & $15.8 \pm 10.6$ & $10.5 \pm 8.9$ & $49.4 \pm 8.6$ & $18.0 \pm 2.0$ \\
\hline \multirow[t]{2}{*}{$>5$ years $(n=15)$} & $17.9 \pm 2.3$ & $9.4 \pm 6.0$ & $4.9 \pm 3.3$ & $45.8 \pm 5.5$ & $16.1 \pm 1.2$ \\
\hline & 0.04 & 0.18 & 0.13 & 0.51 & 0.03 \\
\hline
\end{tabular}

E1: proctitis; E2: left sided colitis; E3: pancolitis; Remission: SCCAI < 3; Mild: SCCAI 3-6; Moderate to severe: SCCAI > 6. ${ }^{*}$ According to Baron's index.

3.3.4. Effect of Steroid Requirement. There was no effect of steroid requirement on any of the parameters (BMI, fat percentage, fat mass, lean mass, FFMI) (Table 3).

3.3.5. Effect of Disease Duration. Among 53 patients, 14 had a disease duration of $<1$ year, 30 had a disease duration between 1 and 5 years, and 9 patients had disease duration $>5$ years. The BMI $\left(17.9 \pm 2.3 \mathrm{~kg} / \mathrm{m}^{2}\right.$ versus $21.4 \pm 2.9 \mathrm{~kg} / \mathrm{m}^{2}$ versus $\left.21.9 \pm 4.8 \mathrm{~kg} / \mathrm{m}^{2}, p=0.04\right)$ and FFMI $(16.1 \pm 1.2$ versus $18.1 \pm 1.7$ versus $18.0 \pm 2, p=0.004)$ were significantly lower in patients with disease duration $>5$ years as compared to patients with disease duration between 1 and 5 years and disease duration $<1$ year. Fat percentage and fat mass also showed a nonsignificant trend towards decline in patients with disease duration $>5$ years (Table 3 ).

\subsection{Effect of Disease Behavior, Clinical Disease Severity, and Disease Duration on Body Composition in Patients of Crohn's Disease}

3.4.1. Effect of Disease Behavior. There was no effect of disease behavior on any of the parameters (BMI, fat percentage, fat mass, lean mass, FFMI) (Table 4).
3.4.2. Effect of Clinical Disease Severity. Of 44 patients, 14 were in clinical remission, 16 had mild disease activity, and 14 had moderate to severe disease activity. Like patients with UC, there was progressive, though not statistically significant, decline in BMI $\left(22.1 \pm 4.2 \mathrm{~kg} / \mathrm{m}^{2}\right.$ versus $19.9 \pm 2.3 \mathrm{~kg} / \mathrm{m}^{2}$ versus $\left.19.7 \pm 4.2 \mathrm{~kg} / \mathrm{m}^{2}, p=0.18\right)$, fat percentage $(18.3 \pm 10 \%$ versus $15.6 \pm 8.5 \%$ versus $12.9 \pm 9.4 \%, p=0.32)$, and fat mass $(11.2 \pm 7 \mathrm{~kg}$ versus $7.9 \pm 4.4 \mathrm{~kg}$ versus $7.2 \pm 5.9 \mathrm{~kg}, p=0.16)$ with increase in disease severity. However, there was no effect of disease severity on lean mass and FFMI (Table 3).

3.4.3. Effect of Disease Duration. Among 44 patients, 9 had a disease duration of $<1$ year, 20 had a disease duration between 1 and 5 years, and 15 patients had disease duration $>5$ years. The lean mass $(40.9 \pm 6.5 \mathrm{~kg}$ versus $43.6 \pm 5.7 \mathrm{~kg}$ versus $52.3 \pm$ $8.3 \mathrm{~kg}, p=0.001)$ and FFMI (16.3 \pm 1.4 versus $17.3 \pm 0.9$ versus $18.6 \pm 2.6, p=0.003$ ) were significantly lower in patients with disease duration between 1 and 5 years and disease duration $>5$ years as compared to patients with disease duration $<1$ year. BMI and fat mass also showed a nonsignificant trend towards decline in patients with disease duration between 1 and 5 years and disease duration $>5$ years (Table 4 ). 
TABLE 4: Effect of disease behavior, clinical severity, and disease duration on body composition in patients with Crohn's disease.

\begin{tabular}{|c|c|c|c|c|c|}
\hline & BMI & Fat percentage & Fat mass in $\mathrm{kg}$ & Lean mass in $\mathrm{kg}$ & FFMI \\
\hline \multicolumn{6}{|l|}{ Disease behavior } \\
\hline $\mathrm{B} 1(n=21)$ & $20.6 \pm 4.4$ & $14.8 \pm 9.7$ & $8.5 \pm 6.9$ & $43.8 \pm 8.3$ & $17.2 \pm 2.0$ \\
\hline $\mathrm{B} 2$ and B3 ( $n=22$ and 1$)$ & $20.5 \pm 2.9$ & $16.4 \pm 9.1$ & $9.1 \pm 5.1$ & $44.4 \pm 7.7$ & $16.9 \pm 1.7$ \\
\hline$p$ value & 0.82 & 0.54 & 0.69 & 0.79 & 0.91 \\
\hline \multicolumn{6}{|l|}{ Disease severity } \\
\hline Remission $(n=14)$ & $22.1 \pm 4.2$ & $18.3 \pm 10.0$ & $11.2 \pm 7.0$ & $46.4 \pm 7.9$ & $17.7 \pm 1.9$ \\
\hline Mild $(n=16)$ & $19.9 \pm 2.3$ & $15.6 \pm 8.5$ & $7.9 \pm 4.4$ & $41.8 \pm 5.7$ & $16.7 \pm 1.2$ \\
\hline Moderate to severe $(n=14)$ & $19.7 \pm 4.2$ & $12.9 \pm 9.4$ & $7.2 \pm 5.9$ & $44.6 \pm 9.4$ & $16.9 \pm 2.3$ \\
\hline$p$ value & 0.18 & 0.32 & 0.16 & 0.27 & 0.31 \\
\hline \multicolumn{6}{|l|}{ Disease duration (years) } \\
\hline$<1$ year $(n=9)$ & $22.5 \pm 5.2$ & $15.6 \pm 8.6$ & $10.9 \pm 7.6$ & $52.3 \pm 8.3$ & $18.6 \pm 2.6$ \\
\hline $1-5$ years $(n=20)$ & $19.4 \pm 3.3$ & $15.1 \pm 10.0$ & $7.8 \pm 5.8$ & $40.9 \pm 6.5$ & $16.3 \pm 1.4$ \\
\hline$>5$ years $(n=15)$ & $20.8 \pm 2.5$ & $16.2 \pm 9.4$ & $8.6 \pm 5.1$ & $43.6 \pm 5.7$ & $17.3 \pm 0.9$ \\
\hline$p$ value & 0.11 & 0.95 & 0.44 & 0.001 & 0.003 \\
\hline
\end{tabular}

B1: inflammatory; B2: stricturing; B3: penetrating; Remission: CDAI < 150; Mild: CDAI: 150-220; Moderate to severe: CDAI > 220.

TABLE 5: Effect of disease behavior, clinical severity, and disease duration on visceral and subcutaneous fat area and visceral to subcutaneous fat ratio $(\mathrm{VF} / \mathrm{SC})$.

\begin{tabular}{|c|c|c|c|}
\hline & Visceral fat area & Subcutaneous fat area & VF/SC ratio \\
\hline \multicolumn{4}{|l|}{ Disease behavior } \\
\hline $\mathrm{B} 1(n=21)$ & $93.1 \pm 59.2$ & $105.8 \pm 79.5$ & $1.32 \pm 0.8$ \\
\hline $\mathrm{B} 2$ and B3 ( $n=22$ and 1$)$ & $114.9 \pm 79.2$ & $108.4 \pm 68.1$ & $1.28 \pm 0.7$ \\
\hline$p$ value & 0.31 & 0.91 & 0.90 \\
\hline \multicolumn{4}{|l|}{ Disease severity } \\
\hline Remission $(n=14)$ & $115.1 \pm 54.1$ & $141.04 \pm 77.9$ & $0.98 \pm 0.4$ \\
\hline Mild $(n=16)$ & $97.6 \pm 54.9$ & $95.9 \pm 58.5$ & $1.37 \pm 0.6$ \\
\hline Moderate to severe $(n=14)$ & $101.8 \pm 99.2$ & $86.2 \pm 75.5$ & $1.53 \pm 0.9$ \\
\hline$p$ value & 0.79 & 0.10 & 0.09 \\
\hline \multicolumn{4}{|l|}{ Disease duration (years) } \\
\hline$<1$ year $(n=9)$ & $106.5 \pm 60.8$ & $145.3 \pm 88.2$ & $1.09 \pm 0.5$ \\
\hline $1-5$ years $(n=20)$ & $93.6 \pm 84.6$ & $88.4 \pm 62.8$ & $1.36 \pm 0.8$ \\
\hline$>5$ years $(n=15)$ & $117.8 \pm 55.4$ & $109.4 \pm 71.3$ & $1.33 \pm 0.6$ \\
\hline$p$ value & 0.61 & 0.15 & 0.63 \\
\hline
\end{tabular}

B1: inflammatory; B2: stricturing; B3: penetrating; Remission: CDAI < 150; Mild: CDAI: 150-220; Moderate to severe: CDAI > 220.

\subsection{Effect of Disease Behavior, Clinical Disease Severity, and Disease Duration on Abdominal Fat in Patients of Crohn's Disease}

3.5.1. Effect of Disease Behavior. There was no difference in visceral and subcutaneous fat area and VF/SC ratio between patients with inflammatory disease versus patients with stricturing/penetrating disease phenotype (Table 5).

3.5.2. Effect of Clinical Disease Severity. There was a statistically nonsignificant trend towards decline in subcutaneous fat area $\left(141.04 \pm 77.9 \mathrm{~cm}^{2}\right.$ versus $95.9 \pm 58.5 \mathrm{~cm}^{2}$ versus $\left.86.2 \pm 75.5 \mathrm{~cm}^{2}, p=0.10\right)$ and increase in VF/SC ratio $(0.98 \pm 0.4$ versus $1.37 \pm 0.6$ versus $1.53 \pm 0.9, p=0.09)$ with increase in disease severity. However, there was no effect of disease severity on visceral fat area.
3.5.3. Effect of Disease Duration. Like the fat mass, the subcutaneous fat area $\left(88.4 \pm 62.8 \mathrm{~cm}^{2}\right.$ versus $109.4 \pm 71.3 \mathrm{~cm}^{2}$ versus $\left.145.3 \pm 88.2 \mathrm{~cm}^{2}, p=0.15\right)$ was also lower in patients with disease duration between 1 and 5 years and disease duration $>5$ years as compared to patients with disease duration less than year. There was no effect of disease duration on visceral fat area and VF/SC ratio.

3.6. Effect of Disease Duration on Body Composition in Patients of $U C$ and $C D$ with Disease Activity. Among 27 patients of $\mathrm{UC}$ with active disease, 6 had a disease duration of $<1$ year, 18 had a disease duration between 1 and 5 years, and 3 patients had disease duration $>5$ years. Like all patients, the effect of disease duration on BMI, fat percentage, fat mass, and FFMI showed similar trends, although the difference was not significant because of small numbers (Table 6). 
TABLE 6: Effect of disease duration on body composition in patients of ulcerative colitis (UC) and Crohn's disease (CD) with active disease (excluding patients in remission).

\begin{tabular}{|c|c|c|c|c|c|}
\hline Disease duration (years) & BMI & Fat percentage & Fat mass in $\mathrm{kg}$ & Lean mass in $\mathrm{kg}$ & FFMI \\
\hline \multicolumn{6}{|l|}{ Ulcerative colitis $(n=27)$} \\
\hline$<1$ year $(n=6)$ & $20.9 \pm 2.8$ & $13.9 \pm 6.7$ & $7.6 \pm 4.3$ & $45.0 \pm 6.5$ & $17.4 \pm 1.1$ \\
\hline $1-5$ years $(n=18)$ & $20.3 \pm 3.2$ & $12.8 \pm 8.1$ & $7.7 \pm 5.7$ & $47.6 \pm 8.1$ & $16.9 \pm 1.8$ \\
\hline$>5$ years $(n=3)$ & $17.1 \pm 2.2$ & $6.1 \pm 3.9$ & $3.4 \pm 2.7$ & $49.5 \pm 5.2$ & $15.5 \pm 1.3$ \\
\hline$p$ value & 0.19 & 0.31 & 0.43 & 0.67 & 0.28 \\
\hline \multicolumn{6}{|l|}{ Crohn's disease $(n=30)$} \\
\hline$<1$ year $(n=5)$ & $20.8 \pm 5.6$ & $11.4 \pm 8.6$ & $7.7 \pm 7.6$ & $50.7 \pm 8.4$ & $17.6 \pm 2.7$ \\
\hline $1-5$ years $(n=17)$ & $19.4 \pm 2.8$ & $15.6 \pm 9.2$ & $7.8 \pm 4.9$ & $40.5 \pm 7.0$ & $15.7 \pm 1.4$ \\
\hline$>5$ years $(n=8)$ & $20.2 \pm 2.5$ & $13.5 \pm 8.9$ & $7.0 \pm 4.6$ & $44.0 \pm 5.6$ & $16.8 \pm 1.0$ \\
\hline$p$ value & 0.65 & 0.62 & 0.95 & 0.03 & 0.05 \\
\hline
\end{tabular}

Among 30 patients of CD with active disease, 5 had a disease duration of $<1$ year, 17 had a disease duration between 1 and 5 years, and 8 patients had disease duration $>5$ years. Like all patients, the effect of disease duration on lean mass and FFMI showed similar trends $(p<0.05)$ (Table 6).

\section{Discussion}

The present study highlights three major findings: low lean mass and fat-free mass in patients with $\mathrm{CD}$ as compared to UC; progressive decline in body fat with increasing disease severity both in UC (clinical as well as endoscopic) and CD (clinical) patients; and decline in fat-free mass with increasing disease duration, again in both UC and CD patients. There was no effect on body composition of disease extent in UC, and disease behavior in CD patients. The main purpose of body composition estimation in these patients is to determine existing differences and set nutritional and therapeutic goals for patients accordingly.

Lower lean mass in CD patients reflects worse nutritional status in CD than UC patients, which could be due to panintestinal and transmural involvement in $\mathrm{CD}$ resulting in poor oral intake and malabsorption. This finding is consistent with other recent studies from Poland [7] and Hungary [9] and 2 recent systematic reviews in children and adults [24, 25]. This difference in lean mass was evident even when there was no difference in the BMI between the two groups, highlighting the fallacy of BMI in the nutritional assessment of patients with IBD. The fat mass was not different between the two groups and previous studies on this aspect have been inconsistent with some studies showing lower fat mass in CD than UC $[7,8]$ and others showing similar fat content between the two groups [26].

Correlation of body composition with disease severity has not been well studied, and the results have been inconsistent across literature. In a previous study done from our center, like the present study, the fat mass in patients with active CD was lower than that of patients in remission, whereas there was no difference in the fat-free mass between active $\mathrm{CD}$ patients and patients in remission in both the studies [10]. However, unlike the present study, the previous study also included healthy controls, and in comparison to controls, the fat mass was only lower in patients with active CD, whereas fat-free mass was lower in both active and remission groups indicating a poor recovery of lean mass in remission. Similarly, in a study of 57 patients with CD from China [11], patients with active $\mathrm{CD}$ had lower BMI than patients with inactive CD and in two other studies from China [11] and Brazil [8], the fat content in patients with active CD was lower than inactive CD. On the other hand, in a systematic review of 19 studies which assessed body composition in adult patients with IBD, there was no consistent association between body composition and disease activity [25]. Endoscopic severity in patients with UC also correlated negatively with fat mass in the present study, and this association was more significant than the association of clinical disease severity, thereby substantiating the association of disease severity and loss of fat mass. This correlation of endoscopic severity with fat mass is a novel concept and has not been shown in previous studies. Increasing disease activity could lead to increased utilization of lipid as a fuel substrate resulting in a reduced fat mass and a preserved fat-free mass [27].

The effect of disease duration on body composition was apparent in both $\mathrm{UC}$ and $\mathrm{CD}$ patients, but the trend was different. Among patients with UC, the effect of disease duration was seen only after 5 years, as BMI, FFMI, fat mass, and fat percentage were lower only in patients with disease duration $>5$ years, whereas, among patients with CD, this effect was seen after 1 year only (lean mass, FFMI, BMI, and fat mass were lower in patients with disease duration $>1$ year) indicating that malnutrition sets in early in the disease course of CD as compared to UC, and this can again be explained by the systemic nature of $\mathrm{CD}$. The muscle active cytokines may stimulate protein degradation and inhibit myogenic differentiation and induce myoblast apoptosis, thereby leading to poor lean mass [28]. The corticosteroids administered to these patients may also have a negative effect on the muscle accrual as steroids are well known to enhance adiposity [29]. An inadequate and often self-restricted diet and reduced physical activity may also contribute to a reduced lean mass in these patients.

Visceral fat has been linked to pathogenesis of CD and studies have linked visceral fat with complicated disease behavior [15], postoperative complications [30, 31], and 
postoperative recurrence in patients with CD [12, 32]. Unlike a previous study we could not correlate visceral fat with disease behavior in our CD patients, and this could possibly be explained by difference in the patient population between the two studies. However, we could link abdominal fat with disease severity as we could demonstrate a nonsignificant negative trend of disease severity with subcutaneous fat (like the fat mass) and a positive trend with VF/SC ratio. Like the fat mass subcutaneous fat also correlated with disease duration with subcutaneous fat being lower in patients with disease duration $>1$ year. We could also demonstrate a significant positive correlation between subcutaneous fat on CT and fat mass (assessed by bioimpedance), thereby indicating that in $\mathrm{CD}$ patients one can assess body composition with the CT. Similar results were demonstrated in a recent study from Australia where fat-free mass was correlated with skeletal muscle area on CT and fat mass was correlated with subcutaneous fat area on CT [13].

Our study has many limitations. The sample size was small and this could explain nonsignificant trend with many associations, because of type II error. Increasing the sample size could have led to more definite conclusions. We did not include healthy controls in our study, but multiple studies including a previous study from our center have already compared body composition in patients with IBD and controls, so comparison with controls would not have added to the results. Comparison of body composition in the same patients at different stages of endoscopic/clinical activity and at different time points (with respect to disease duration) would also have given better results.

To conclude, Crohn's disease patients are at a higher risk of malnutrition than ulcerative colitis patients, there is a loss of fat mass with increasing disease activity in IBD patients, and their nutritional status deteriorates with increasing disease duration (earlier in CD). Therefore, proper assessment of nutritional status along with proper measures to improve these deficiencies is very important to improve the quality of life in patients with IBD.

\section{Conflicts of Interest}

The authors declare that there are no conflicts of interest regarding the publication of this paper.

\section{References}

[1] V. Ahuja and R. K. Tandon, "Inflammatory bowel disease in the Asia-Pacific area: A comparison with developed countries and regional differences," Journal of Digestive Diseases, vol. 11, no. 3, pp. 134-147, 2010.

[2] V. Ahuja and R. K. Tandon, "Inflammatory bowel disease: The Indian augury," Indian Journal of Gastroenterology, vol. 31, no. 6, pp. 294-296, 2012.

[3] P. Singh, A. Ananthakrishnan, and V. Ahuja, "Pivot to Asia: Inflammatory bowel disease burden," Intestinal Research, vol. 15, no. 1, pp. 138-141, 2017.

[4] C. R. Fleming, "Nutrition in Patients With Crohn's Disease: Another Piece of the Puzzle," Journal of Parenteral and Enteral Nutrition, vol. 19, no. 2, pp. 93-94, 1995.
[5] D. Royall, G. R. Greenberg, J. P. Allard, J. P. Baker, J. E. Harrison, and K. N. Jeejeebhoy, "Critical assessment of body-composition measurements in malnourished subjects with Crohn's disease: the role of bioelectric impedance analysis," American Journal of Clinical Nutrition, vol. 59, no. 2, pp. 325-330, 1994.

[6] L. Tjellesen, P. K. Nielsen, and M. Staun, "Body composition by dual-energy X-ray absorptiometry in patients with Crohn's disease," Scandinavian Journal of Gastroenterology, vol. 33, no. 9, pp. 956-960, 1998.

[7] P. Więch, M. Binkowska-Bury, and B. Korczowski, "Body composition as an indicator of the nutritional status in children with newly diagnosed ulcerative colitis and Crohn's disease-a prospective study," Przegląd Gastroenterologiczny, vol. 12, no. 1, pp. 55-59, 2017.

[8] I. R. Back, S. S. Marcon, N. M. Gaino, D. S. B. Vulcano, M. S. Dorna, and L. Y. Sassaki, "Body composition in patients with Crohn's disease and ulcerative colitis," Arq Gastroenterol, vol. 54, no. 2, pp. 109-114, 2017.

[9] Á. A. Csontos, A. Molnár, Z. Piri, E. Pálfi, and P. Miheller, "Malnutrition risk questionnaire combined with body composition measurement in malnutrition screening in inflammatory bowel disease," Revista Española de Enfermedades Digestivas, vol. 109, no. 1, pp. 26-32, 2017.

[10] J. Benjamin, G. Makharia, V. Ahuja, and Y. K. Joshi, "Body composition in Indian patients with Crohn's disease during active and remission phase," Trop Gastroenterol, vol. 32, no. 4, pp. 285-291, 2011.

[11] T. Yan, L. Li, Q. Wu, X. Gao, P. Hu, and Q. He, "[Analysis of body composition in patients with Crohn's disease]," Zhonghua Wei Chang Wai Ke Za Zhi, vol. 17, no. 10, pp. 981-984, 2014.

[12] D. Q. Holt, G. T. Moore, B. J. G. Strauss, A. L. Hamilton, P. De Cruz, and M. A. Kamm, "Visceral adiposity predicts postoperative Crohn's disease recurrence," Alimentary Pharmacology \& Therapeutics, vol. 45, no. 9, pp. 1255-1264, 2017.

[13] D. Q. Holt, B. J. G. Strauss, K. K. Lau, and G. T. Moore, "Body composition analysis using abdominal scans from routine clinical care in patients with Crohn's Disease," Scandinavian Journal of Gastroenterology, vol. 51, no. 7, pp. 842-847, 2016.

[14] C. Büning, C. Von Kraft, M. Hermsdorf et al., "Visceral adipose tissue in patients with Crohn's disease correlates with disease activity, inflammatory markers, and outcome," Inflammatory Bowel Diseases, vol. 21, no. 11, pp. 2590-2597, 2015.

[15] B. Erhayiem, R. Dhingsa, C. J. Hawkey, and V. Subramanian, "Ratio of visceral to subcutaneous fat area is a biomarker of complicated Crohn's Disease," Clinical Gastroenterology and Hepatology, vol. 9, no. 8, pp. 684-687.e1, 2011.

[16] G. van Assche, A. Dignass, J. Panes et al., “The second European evidence-based consensus on the diagnosis and management of Crohn's disease: definitions and diagnosis," Journal of Crohn's and Colitis, vol. 4, no. 1, pp. 7-27, 2010.

[17] M. S. Silverberg, J. Satsangi, T. Ahmad et al., "Toward an integrated clinical, molecular and serological classification of inflammatory bowel disease: report of a Working Party of the 2005 Montreal World Congress of Gastroenterology," Canadian Journal of Gastroenterology \& Hepatology, vol. 19, pp. 5-36, 2005.

[18] W. R. Best, J. M. Becktel, J. W. Singleton, and F. Kern Jr., "Development of a Crohn's disease activity index. National cooperative Crohn's disease study," Gastroenterology, vol. 70, no. 3, pp. 439444, 1976.

[19] A. Dignass, R. Eliakim, F. Magro et al., "Second European evidence-based consensus on the diagnosis and management 
of ulcerative colitis part 1: definitions and diagnosis," Journal of Crohn's and Colitis, vol. 6, no. 10, pp. 965-990, 2012.

[20] R. S. Walmsley, R. C. S. Ayres, R. E. Pounder, and R. N. Allan, "A simple clinical colitis activity index," Gut, vol. 43, no. 1, pp. 29-32, 1998.

[21] J. H. Baron, A. M. Connell, and J. E. Lennard-Jones, "Variation Between Observers in Describing Mucosal Appearances in Proctocolitis," British Medical Journal, vol. 1, no. 5375, pp. 8992, 1964.

[22] R. Y. T. Sung, P. Lau, C. W. Yu, P. K. W. Lam, and E. A. S. Nelson, "Measurement of body fat using leg to leg bioimpedance," Archives of Disease in Childhood, vol. 85, no. 3, pp. 263-267, 2001.

[23] E. J. Boyko, W. Y. Fujimoto, D. L. Leonetti, and L. NewellMorris, "Visceral adiposity and risk of type 2 diabetes: a prospective study among Japanese Americans," Diabetes Care, vol. 23, no. 4, pp. 465-471, 2000.

[24] D. Thangarajah, M. J. Hyde, V. K. S. Konteti, S. Santhakumaran, G. Frost, and J. M. E. Fell, "Systematic review: Body composition in children with inflammatory bowel disease," Alimentary Pharmacology \& Therapeutics, vol. 42, no. 2, pp. 142-157, 2015.

[25] R. V. Bryant, M. J. Trott, F. D. Bartholomeusz, and J. M. Andrews, "Systematic review: body composition in adults with inflammatory bowel disease," Alimentary Pharmacology \& Therapeutics, vol. 38, no. 3, pp. 213-225, 2013.

[26] R. Rocha, G. O. Santana, N. Almeida, and A. C. Lyra, "Analysis of fat and muscle mass in patients with inflammatory bowel disease during remission and active phase," British Journal of Nutrition, vol. 101, no. 5, pp. 676-679, 2009.

[27] G. Mingrone, A. V. Greco, G. Benedetti et al., "Increased resting lipid oxidation in Crohn's disease," Digestive Diseases and Sciences, vol. 41, no. 1, pp. 72-76, 1996.

[28] J. M. Burnham, J. Shults, E. Semeao et al., "Body-composition alterations consistent with cachexia in children and young adults with Crohn disease," American Journal of Clinical Nutrition, vol. 82, no. 2, pp. 413-420, 2005.

[29] E. Canalis, R. C. Pereira, and A. M. Delany, "Effects of glucocorticoids on the skeleton," Journal of Pediatric Endocrinology and Metabolism, vol. 15, no. 5, pp. 1341-1345, 2002.

[30] T. M. Connelly, R. M. Juza, W. Sangster, R. Sehgal, R. F. Tappouni, and E. Messaris, "Volumetric fat ratio and not body mass index is predictive of ileocolectomy outcomes in Crohn's disease patients," Digestive Surgery, vol. 31, no. 3, pp. 219-224, 2014.

[31] Z. Ding, X.-R. Wu, E. M. Remer et al., "Association between high visceral fat area and postoperative complications in patients with Crohn's disease following primary surgery," Colorectal Disease, vol. 18, no. 2, pp. 163-172, 2016.

[32] Y. Li, W. Zhu, J. Gong et al., "Visceral fat area is associated with a high risk for early postoperative recurrence in crohn's disease," Colorectal Disease, vol. 17, no. 3, pp. 225-234, 2015. 


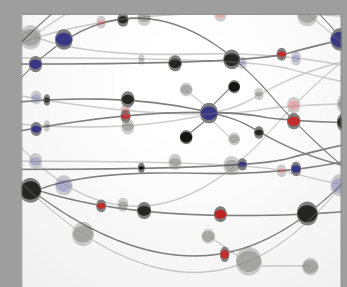

The Scientific World Journal
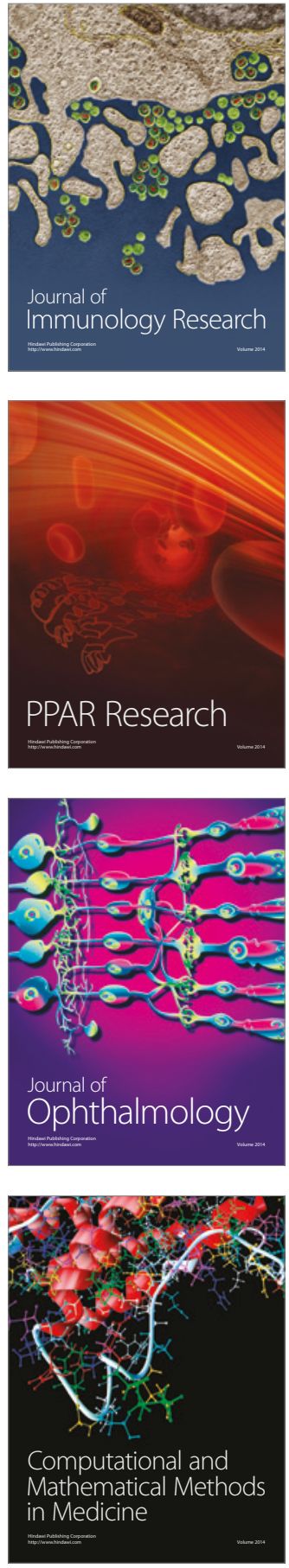

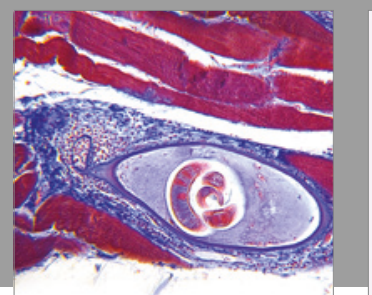

Gastroenterology Research and Practice
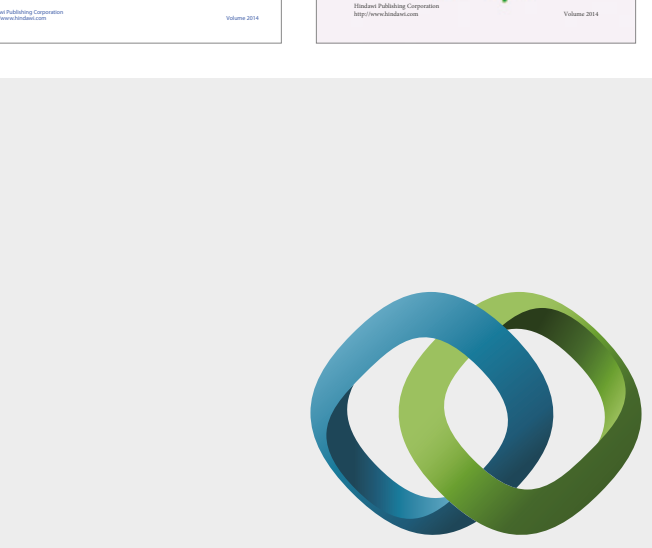

\section{Hindawi}

Submit your manuscripts at

https://www.hindawi.com
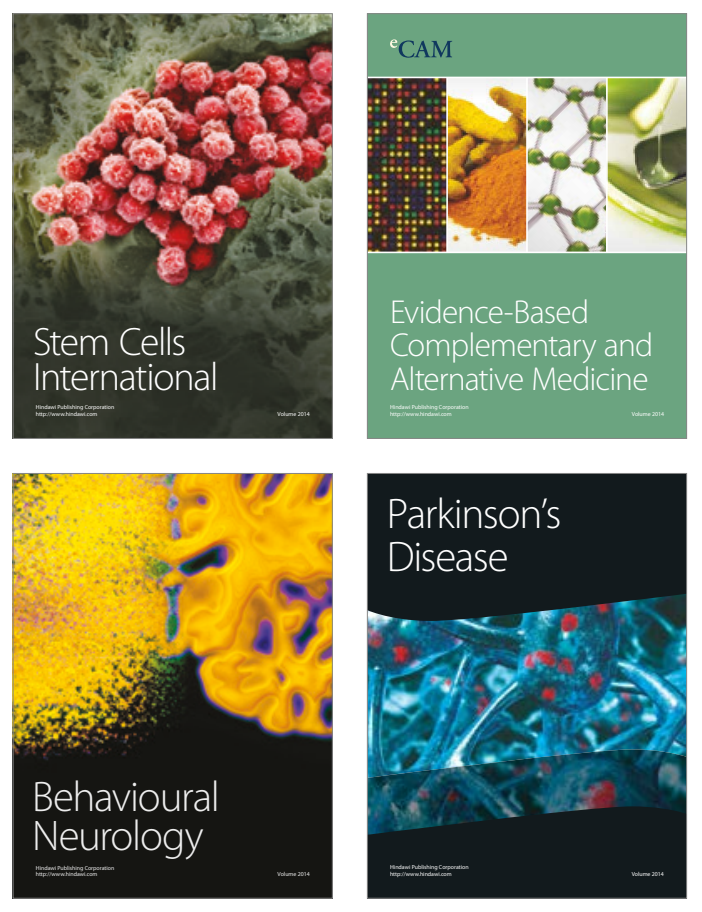
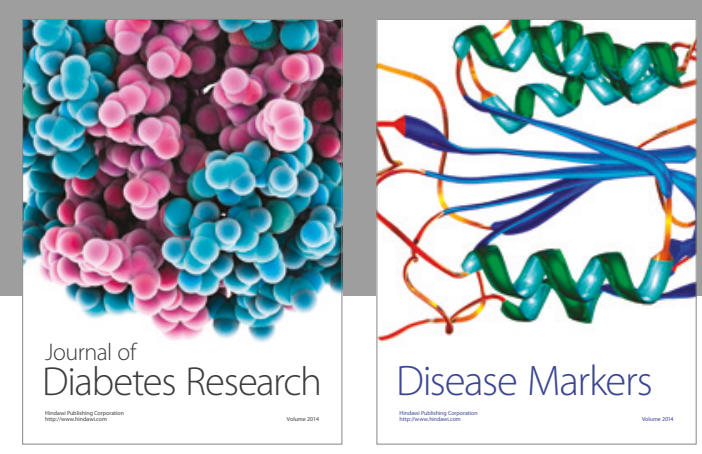

Disease Markers
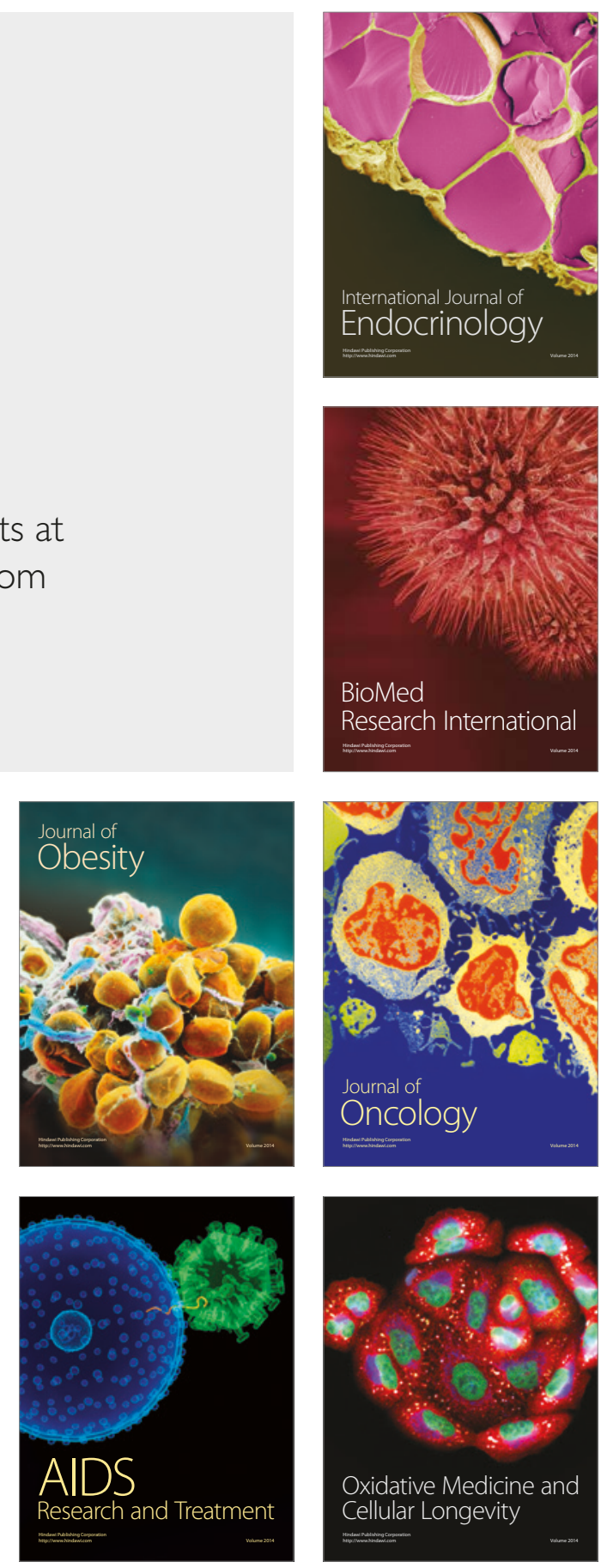